\title{
ARE INCREASING 5-YEAR SURVIVAL RATES EVIDENCE OF SUCCESS AGAINST CANCER? A REEXAMINATION USING DATA FROM THE U.S. AND AUSTRALIA
}

\author{
Frank R. Lichtenberg \\ Working Paper 16051 \\ http://www.nber.org/papers/w16051 \\ NATIONAL BUREAU OF ECONOMIC RESEARCH \\ 1050 Massachusetts Avenue \\ Cambridge, MA 02138 \\ June 2010
}

The views expressed herein are those of the author and do not necessarily reflect the views of the National Bureau of Economic Research.

NBER working papers are circulated for discussion and comment purposes. They have not been peerreviewed or been subject to the review by the NBER Board of Directors that accompanies official NBER publications.

(C) 2010 by Frank R. Lichtenberg. All rights reserved. Short sections of text, not to exceed two paragraphs, may be quoted without explicit permission provided that full credit, including $\odot$ notice, is given to the source. 
Are Increasing 5-Year Survival Rates Evidence of Success Against Cancer? A reexamination using data from the U.S. and Australia

Frank R. Lichtenberg

NBER Working Paper No. 16051

June 2010

JEL No. C2,I12,J11,O4

\begin{abstract}
Previous investigators argued that increasing 5-year survival for cancer patients should not be taken as evidence of improved prevention, screening, or therapy, because they found little correlation between the change in 5-year survival for a specific tumor and the change in tumor-related mortality. However, they did not control for the change in incidence, which influences mortality and is correlated with 5-year survival.
\end{abstract}

We reexamine the question of whether increasing 5-year survival rates constitute evidence of success against cancer, using data from both the U.S. and Australia. When incidence growth is controlled for, there is a highly significant correlation, in both countries, between the change in 5-year survival for a specific tumor and the change in tumor-related mortality. The increase in the relative survival rate is estimated to have reduced the unconditional mortality rate by about $15 \%$ in the U.S. between 1976 and 2002, and by about 15\% in Australia between 1984 and 2001.

While the change in the 5-year survival rate is not a perfect measure of progress against cancer, in part because it is potentially subject to lead-time bias, it does contain useful information; its critics may have been unduly harsh. Part of the long-run increase in 5-year cancer survival rates is due to improved prevention, screening, or therapy.

Frank R. Lichtenberg

Columbia University

504 Uris Hall

3022 Broadway

New York, NY 10027

and NBER

frl1@columbia.edu 


\section{Introduction}

The 5-year relative survival rate of American patients diagnosed with cancer increased from $50.1 \%$ in $1975-1977$ to $67.8 \%$ in $1999-2005$. In a previous, frequently-cited paper, ${ }^{1}$ Welch et al (2000) argued that "improving 5-year survival over time...should not be taken as evidence of improved prevention, screening, or therapy." They argued that "while 5-year survival is a perfectly valid measure to compare cancer therapies in a randomized trial, comparisons of 5-year survival rates across time (or place) may be extremely misleading. If cancer patients in the past always had palpable tumors at the time of diagnosis while current cancer patients include those diagnosed with microscopic abnormalities, then 5-year survival would be expected to increase over time even if new screening and treatment strategies are ineffective. To avoid the problems introduced by changing patterns of diagnosis, observers have argued that progress against cancer be assessed using population-based mortality rates."

To determine whether improving 5-year survival over time should be taken as evidence of improved prevention, screening, or therapy, Welch et al used data from the Surveillance, Epidemiology and End Results (SEER) program to compare changes in 5-year survival, mortality rates, and cancer incidence rates for the 20 most common solid tumor types from 1950 to 1995. For each tumor, they calculated the absolute difference in 5-year survival from 1989-1995 and from 1950-1954. They used simple correlation to analyze the relationship between the variables, and found that there was little correlation between the change in 5-year survival for a specific tumor and the change in tumor-related mortality (Pearson $r=.00$; Spearman $r=-.07$ ). On the other hand, the change in 5-year survival was positively correlated with the change in the tumor incidence rate (Pearson $r=$ +.49 ; Spearman $r=+.37$ ). They concluded that "improving 5-year survival over time...may not reflect reduced disease burden and should not be taken as evidence of improved prevention, screening, or therapy."2

In this paper, I reexamine the question of whether increasing 5-year survival rates constitute evidence of success against cancer, using data from both the U.S. and Australia. Like Welch et al, I analyze the correlation across cancer sites between changes in 5-year survival rates and changes in population-based mortality rates. But in contrast to them, I analyze the partial correlation between these two variables, controlling for changes in incidence. I argue that changes in

\footnotetext{
${ }^{1}$ According to JAMA, Welch et al had been cited 131 times as of 9/30/2009.

${ }^{2}$ Other authors have argued, in articles in both the medical literature and the popular press, that little or no progress has been made against cancer, which implies that the 5-year survival rate is not a meaningful indicator. For example, Bailar and Gornik (1997) argued that "the effect of new treatments for cancer on mortality has been largely disappointing," and Leaf (2004) published an article entitled "Why we're losing the war on cancer, and how to win it."
} 
population-based mortality rates should depend on changes in incidence as well as changes in 5-year survival rates. Since, as Welch et al found and I confirm, changes in incidence are strongly positively correlated across cancer sites with changes in 5-year survival rates, failure to control for changes in incidence results in a seriously biased estimate of the relationship (or correlation) between changes in 5-year survival rates and changes in population-based mortality rates.

\section{Methods}

Welch et al analyzed the correlation across cancer sites between changes in 5-year survival rates and changes in population-based mortality rates. The 5-year survival rate may be interpreted as a conditional probability: the probability of not dying between time $t$ and time $\mathrm{t}+5$ (where time is measured in years), conditional on being diagnosed with cancer at time t. The population-based mortality rate may be interpreted as an unconditional probability: the probability of dying from cancer between time $\mathrm{t}$ and time $\mathrm{t}+1$.

According to the law of total probability ${ }^{3}$, conditional and unconditional probabilities are related as follows:

$\mathrm{P}(\mathrm{A})=\mathrm{P}(\mathrm{A} \mid \mathrm{B}) * \mathrm{P}(\mathrm{B})+\mathrm{P}\left(\mathrm{A} \mid \mathrm{B}^{\prime}\right) * \mathrm{P}\left(\mathrm{B}^{\prime}\right)$

where

$\mathrm{P}(\mathrm{A})=$ probability that event $\mathrm{A}$ occurs

$\mathrm{P}(\mathrm{A} \mid \mathrm{B})=$ the conditional probability that event $\mathrm{A}$ occurs given that event $\mathrm{B}$ has occurred

$\mathrm{P}\left(\mathrm{B}^{\prime}\right)=$ probability that event $\mathrm{B}$ does not occur

Applying the law of total probability to cancer mortality rates,

$$
\begin{array}{r}
\mathrm{P}(\text { death })=\mathrm{P}(\text { death } \mid \text { diagnosis }) * \mathrm{P}(\text { diagnosis }) \\
+\mathrm{P}(\text { death } \mid \text { no diagnosis }) *(1-\mathrm{P}(\text { diagnosis })) \\
=(1-\mathrm{P}(\text { survival } \mid \text { diagnosis })) * \mathrm{P}(\text { diagnosis })+ \\
\mathrm{P}(\text { death } \mid \text { no diagnosis }) *(1-\mathrm{P}(\text { diagnosis }))
\end{array}
$$

We have data corresponding to three of the four probabilities in eq. (1): the unconditional mortality rate $(\mathrm{P}($ death $))$, the conditional survival rate $(\mathrm{P}$ (survival | diagnosis $)$ ), and the cancer incidence rate $(\mathrm{P}($ diagnosis $))$. We lack data on $\mathrm{P}($ death

${ }^{3}$ http://www.stats.gla.ac.uk/steps/glossary/probability.html\# 
( no diagnosis): the probability of dying from cancer, conditional on having not been diagnosed with cancer. However, we think it is reasonable to assume that this probability is small: among people who have never been diagnosed with cancer, the probability of dying from cancer is quite small. ${ }^{4}$ If this is the case,

$\mathrm{P}($ death $) \approx(1-\mathrm{P}($ survival $\mid$ diagnosis $)) * \mathrm{P}($ diagnosis $)$

$\ln (\mathrm{P}($ death $)) \approx \ln (1-\mathrm{P}($ survival $\mid$ diagnosis $))+\ln (\mathrm{P}($ diagnosis $))$

$\Delta \ln (\mathrm{P}($ death $)) \approx \Delta \ln (1-\mathrm{P}($ survival $\mid$ diagnosis $))+\Delta \ln (\mathrm{P}($ diagnosis $))$

$\mathrm{P}$ (death) can be measured by the unconditional mortality rate (mort_uncond), and $\mathrm{P}$ (diagnosis) can be measured by the incidence rate (incidence). The 5-year survival rate (surv_5_year) is a good indicator of $\mathrm{P}$ (survival | diagnosis)). Hence

$\Delta \ln ($ mort_uncond $) \approx \Delta \ln \left(1-\operatorname{surv\_ 5\_ year}\right)+\Delta \ln ($ incidence $)$

Eq. (2) implies that the percentage change in the unconditional mortality rate (cancer deaths per 100,000 population) should depend on the percent change in one minus the 5-year survival rate and on the percent change in incidence (cancer cases diagnosed per 100,000 population). Figure 1, which shows aggregate time series data on unconditional mortality rates and incidence rates, provides support for the hypothesis that there is a strong link between unconditional mortality and incidence.

Consider the regression equation

$\Delta \ln ($ mort_uncond $)=\alpha+\beta_{1} \Delta \ln \left(1-\operatorname{surv\_ 5\_ year}\right)+\beta_{2} \Delta \ln ($ incidence $)+\varepsilon$

Although eq. (2) implies that $\beta_{1}=\beta_{2}=1$ and that $\alpha=0$, for a variety of reasons these restrictions are unlikely to be satisfied in practice. One important reason is sampling error: although unconditional mortality is measured using data on the complete census of death certificates, 5-year survival rates and incidence are subject to sampling error because they are based on data from cancer registries covering much less than one-fourth of the U.S. population. Sampling error is likely to bias estimates of $\beta_{1}$ and $\beta_{2}$ towards zero.

If eq. (3) is the "true model" of unconditional mortality, i.e. the change in unconditional mortality depends on both the change in the 5-year survival rate and the change in the incidence rate, but we estimate the simple regression of

\footnotetext{
${ }^{4}$ The cancer incidence rate is 2.5 times as high as the cancer mortality rate: 2006 U.S. ageadjusted incidence and mortality rates were 456.2 and 181.1, respectively.
} 
Figure 1

Age-adjusted cancer incidence and unconditional mortality rates, all cancer sites combined
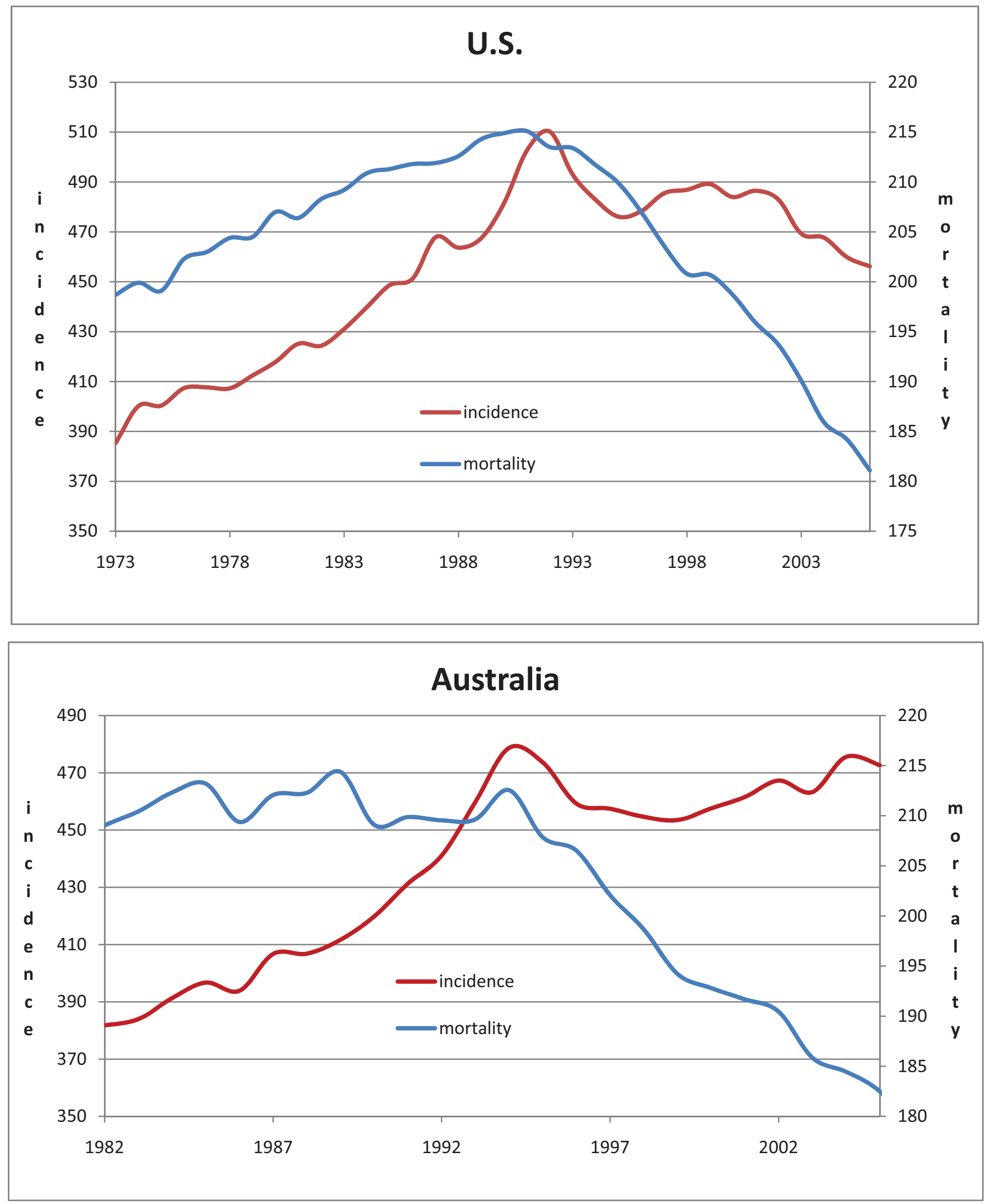
$\Delta \ln$ (mort_uncond) on $\Delta \ln (1$ - surv_5_year), the coefficient on $\Delta \ln (1$ surv_5_year) will be biased if $\Delta \ln (1-\operatorname{surv} 5$ 5_year) and $\Delta \ln$ (incidence) are correlated. ${ }^{5}$ Let

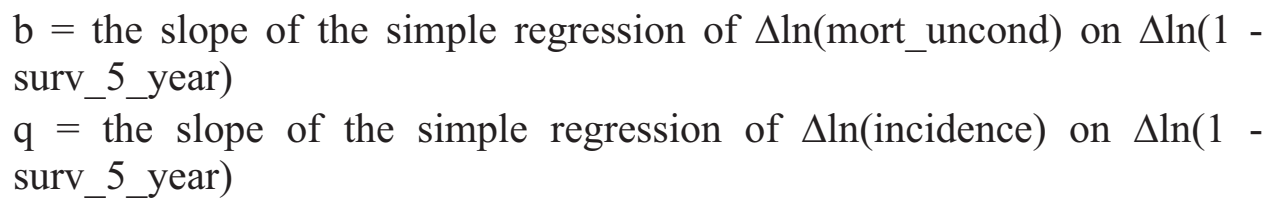

Then it can be shown that $E(b)=\beta_{1}+\beta_{2} q$. Welch et al found that the change in 5 -year survival was positively correlated with the change in the tumor incidence rate (Pearson $r=+.49$; Spearman $r=+.37$ ), which implies that $\mathrm{q}<0$ and that $\mathrm{E}(\mathrm{b})<$ $\beta_{1}$ : the slope of the simple regression of $\Delta \ln$ (mort_uncond) on $\Delta \ln (1$ surv_5_year) will underestimate the true effect of the change in the conditional mortality rate on the unconditional mortality rate. Since cancers with the largest increases in survival rates tended to have the largest increases in incidence (which has a positive effect on unconditional mortality), if we fail to control for incidence we will underestimate the correlation between the conditional mortality rate and the unconditional mortality rate.

Welch et al implicitly hypothesized that the "true model" of the change in the unconditional mortality rate is:

$\mathrm{m}=\beta \mathrm{s}^{*}+\mathrm{u}$

where

$\mathrm{m}=$ the change in the unconditional mortality rate

$\mathrm{s}^{*}=$ the true change in the conditional mortality rate $(=1-$ the true change in the conditional survival rate)

$\mathrm{u}=\mathrm{a}$ disturbance

The true change in the conditional mortality rate is not observed. Instead, we observe a noisy indicator of $\mathrm{s}^{*}$ :

$\mathrm{s}=\mathrm{s}^{*}+\mathrm{e}$

where

$\mathrm{s}=$ the measured change in the conditional mortality rate

${ }^{5}$ http://en.wikipedia.org/wiki/Omitted-variable bias 


$$
\mathrm{e}=\text { measurement error }
$$

We might think of $\mathrm{s}^{*}$ as the mortality rate measured from the true date of onset of the disease, and $\mathrm{s}$ as the mortality rate measured from the date of diagnosis of the disease. The measurement error is assumed to be uncorrelated with $\mathrm{s}^{*}$.

It is well known that measurement error will bias the estimate of $\beta$ towards zero. If $\mathrm{b}\left(=\Sigma \mathrm{ms} / \Sigma \mathrm{s}^{2}\right)$ is the coefficient from the simple regression of $\mathrm{m}$ on $\mathrm{s}$, then $\mathrm{E}(\mathrm{b})=\beta\left[\operatorname{var}\left(\mathrm{s}^{*}\right) /\left\{\operatorname{var}\left(\mathrm{s}^{*}\right)+\operatorname{var}(\mathrm{e})\right\}\right]$. According to Welch et al, the fact that $\mathrm{b}$ is small and insignificant is due to large measurement error (high $\operatorname{var}(\mathrm{e})$ ), and leadtime bias is a major source of this error.

But the reasoning above implies that there is an alternative possible explanation for the lack of a simple correlation between $\mathrm{m}$ and $\mathrm{s}$ : the "true model" of the change in the unconditional mortality rate is not $\mathrm{m}=\beta \mathrm{s}^{*}+\mathrm{u}$, but $\mathrm{m}=\beta \mathrm{s}^{*}+\gamma \mathrm{i}+$ $\mathrm{u}$ (where $\mathrm{i}=$ the change in the incidence rate), and $\operatorname{corr}\left(\mathrm{s}^{*}, \mathrm{i}\right)<0$. The lack of a simple correlation between changes in unconditional and conditional mortality rates may be due to omitted-variable bias rather than measurement error in 5-year relative survival rates.

\section{Data}

U.S. data. Data on age-adjusted unconditional mortality rates, 5-year relative survival rates, and age-adjusted incidence rates, were obtained from SEER Cancer Query Systems (http://seer.cancer.gov/canques/). Annual data on unconditional

mortality and incidence are available for 1973-2006. Data on 5-year relative survival rates are available for patients diagnosed during certain periods. The earliest period of diagnosis is 1975-1977; the latest period is 1999-2005. We will present estimates of several versions of the following model (based on eq. (3)) using U.S. data on 24 cancer sites:

$$
\begin{aligned}
& \ln \left(\text { mort_uncond }_{2006} / \text { mort_uncond }_{1980}\right)=\alpha+ \\
& \beta_{1} \ln \left(\left(1-\text { surv_5_year }_{1999-2005}\right) /\left(1-\text { surv_5_year }_{1975-1977}\right)\right)+ \\
& \beta_{2} \ln \left(\text { incidence }_{2002} / \text { incidence }_{1976}\right)+\varepsilon
\end{aligned}
$$

According to this model, the unconditional mortality rate in year $t$ depends on the incidence rate in year t-4 and a moving average of conditional survival rates of patients diagnosed 1-7 years prior to year t. We also estimated models in which the incidence rate in year $\mathrm{t}-4$ was replaced by a moving average of incidence rates 4-7 years prior to year $t$. This had virtually no effect on the estimates, which is not surprising, since incidence rates are highly serially correlated.

The complete U.S. dataset is shown in Appendix Table 1. 
Australian data. Data on age-adjusted unconditional mortality rates and ageadjusted incidence rates, were obtained from Australian Cancer Incidence and Mortality (ACIM) books

(http://www.aihw.gov.au/cancer/data/acim books/index.cfm). Data on 5-year relative survival rates were obtained from Table 2.3 of the publication Cancer survival and prevalence in Australia: cancers diagnosed from 1982 to 2004 (http://www.aihw.gov.au/publications/index.cfm/title/10484).

Annual data on unconditional mortality and incidence are available for 19822005. Data on 5-year relative survival rates are available for patients diagnosed during certain periods. The earliest period of diagnosis is 1982-1986; the latest period is 1998-2004. We will present estimates of several versions of the following model using Australian data on 20 cancer sites:

$\ln \left(\right.$ mort_uncond $_{2003} /$ mort_uncond $\left._{1987}\right)=\alpha+$

$$
\begin{aligned}
& \beta_{1} \ln \left(\left(1-\text { surv } \_5 \_ \text {year }_{1998-2004}\right) /(1 \text { - surv_5_year } 1982-1986)\right)+ \\
& \beta_{2} \ln \left(\text { incidence }_{1998} / \text { incidence }_{1982}\right)+\varepsilon
\end{aligned}
$$

The complete Australian dataset is shown in Appendix Table 2.

The disturbances of eqs. (4) and (5) are likely to be heteroskedastic: cancer sites with the lowest average mortality rates are likely to exhibit the largest positive or negative percentage changes in mortality rates. In this case, these equations should be estimated using weighted least-squares (rather than ordinary least-squares), weighting by the cancer site's average unconditional mortality rate. We will estimate three versions of each equation: equally weighted, weighted by the mean of the initial and final incidence rates, and weighted by the mean of the initial and final unconditional mortality rates. Descriptive statistics for both the U.S. and Australia are shown in Table 1.

\section{Results}

Estimates of eqs. (4) and (5) are presented in Table 2. To reveal the importance of controlling for incidence, we present estimates of these equations with and without imposing restrictions on the parameters. First, we impose the restriction $\beta_{2}=0$, which is equivalent to examining the effect of relative survival on unconditional mortality, without controlling for incidence. Second, we impose the restriction $\beta_{1}=0$, which is equivalent to examining the effect of incidence on unconditional mortality, without controlling for relative survival. Third, we impose neither restriction. 
Table 1

Descriptive statistics

\begin{tabular}{|c|c|c|c|c|c|}
\hline & $\mathrm{N}$ & $\begin{array}{c}\text { Weighted } \\
\text { Mean }\end{array}$ & $\begin{array}{l}\text { Weighted } \\
\text { Std Dev }\end{array}$ & Min & Max \\
\hline & \multicolumn{5}{|c|}{ USA } \\
\hline In(mort_uncond ${ }_{2006} /$ mort_uncond $\left.{ }_{1980}\right)$ & 24 & -0.18 & 0.70 & -1.20 & 0.16 \\
\hline $\ln \left(\left(1\right.\right.$ - surv_5_year $\left.{ }_{1999-2005}\right) /\left(1\right.$ - surv_5_year $\left.\left.{ }_{1975-1977}\right)\right)$ & 24 & -1.15 & 5.62 & -5.74 & 0.10 \\
\hline \multirow[t]{2}{*}{ In(incidence ${ }_{2002} /$ incidence $\left._{1976}\right)$} & 24 & 0.14 & 0.84 & -0.66 & 0.85 \\
\hline & \multicolumn{5}{|c|}{ Australia } \\
\hline In(mort_uncond ${ }_{2003} /$ mort_uncond $\left.{ }_{1987}\right)$ & 20 & -0.18 & 0.56 & -0.76 & 0.04 \\
\hline $\ln \left((1\right.$ - surv_5_year $1998-2004) /\left(1\right.$ - surv_5_year $\left.\left.{ }_{1982-1986}\right)\right)$ & 20 & -0.28 & 1.02 & -1.06 & 0.21 \\
\hline In(incidence ${ }_{1998} /$ incidence $_{1982}$ ) & 20 & 0.09 & 0.77 & -0.44 & 0.66 \\
\hline
\end{tabular}

Note: Observations are weighted by the cancer site's average unconditional mortality rate. 
Table 2

Estimates of Eqs. (4) and (5)

\begin{tabular}{|c|c|c|c|c|c|c|c|c|c|}
\hline Column & 1 & 2 & 3 & 4 & 5 & 6 & 7 & 8 & 9 \\
\hline $\begin{array}{l}\text { Restrictio } \\
\text { ns } \\
\text { imposed }\end{array}$ & $\beta_{2}=0$ & $\beta_{1}=0$ & none & $\beta_{2}=0$ & $\beta_{1}=0$ & none & $\beta_{2}=0$ & $\beta_{1}=0$ & none \\
\hline & \multicolumn{3}{|c|}{ equally weighted } & \multicolumn{3}{|c|}{ weighted by incidence } & \multicolumn{3}{|c|}{ weighted by mortality rate } \\
\hline & \multicolumn{9}{|c|}{ US $(N=24)$} \\
\hline \multicolumn{10}{|l|}{$\underline{\beta_{1}}$} \\
\hline Estimate & 0.040 & & 0.140 & 0.025 & & 0.089 & 0.040 & & 0.127 \\
\hline StdErr & 0.067 & & 0.067 & 0.019 & & 0.023 & 0.025 & & 0.025 \\
\hline tValue & 0.597 & & 2.096 & 1.286 & & 3.942 & 1.599 & & 4.981 \\
\hline Probt & 0.557 & & 0.048 & 0.212 & & 0.001 & 0.124 & & 0.000 \\
\hline \multicolumn{10}{|l|}{$\beta_{2}$} \\
\hline Estimate & & 0.405 & 0.627 & & 0.147 & 0.613 & & 0.203 & 0.810 \\
\hline StdErr & & 0.196 & 0.211 & & 0.138 & 0.160 & & 0.171 & 0.170 \\
\hline tValue & & 2.068 & 2.974 & & 1.059 & 3.836 & & 1.183 & 4.759 \\
\hline Probt & & 0.051 & 0.007 & & 0.301 & 0.001 & & 0.250 & 0.000 \\
\hline \multicolumn{10}{|l|}{$\underline{\alpha}$} \\
\hline Estimate & -0.218 & -0.279 & -0.217 & -0.205 & -0.292 & -0.224 & -0.134 & -0.208 & -0.146 \\
\hline StdErr & 0.086 & 0.072 & 0.074 & 0.062 & 0.059 & 0.049 & 0.059 & 0.057 & 0.042 \\
\hline tValue & -2.539 & -3.852 & -2.940 & -3.283 & -4.922 & -4.549 & -2.298 & -3.636 & -3.509 \\
\hline Probt & 0.019 & 0.001 & 0.008 & 0.003 & 0.000 & 0.000 & 0.031 & 0.001 & 0.002 \\
\hline & \multicolumn{9}{|c|}{ Australia $(\mathrm{N}=20)$} \\
\hline \multicolumn{10}{|l|}{$\beta_{1}$} \\
\hline Estimate & 0.126 & & 0.787 & -0.086 & & 0.442 & -0.047 & & 0.538 \\
\hline StdErr & 0.162 & & 0.134 & 0.118 & & 0.158 & 0.127 & & 0.176 \\
\hline tValue & 0.778 & & 5.850 & -0.730 & & 2.801 & -0.369 & & 3.058 \\
\hline Probt & 0.447 & & 0.000 & 0.475 & & 0.012 & 0.717 & & 0.007 \\
\hline \multirow{2}{*}{\multicolumn{10}{|c|}{$\beta_{2}$}} \\
\hline & & & & & & & & & \\
\hline Estimate & & 0.338 & 1.033 & & 0.343 & 0.818 & & 0.319 & 0.921 \\
\hline StdErr & & 0.176 & 0.158 & & 0.132 & 0.203 & & 0.152 & 0.234 \\
\hline tValue & & 1.924 & 6.538 & & 2.597 & 4.021 & & 2.099 & 3.944 \\
\hline Probt & & 0.070 & 0.000 & & 0.018 & 0.001 & & 0.050 & 0.001 \\
\hline \multicolumn{10}{|l|}{$\underline{\alpha}$} \\
\hline Estimate & -0.205 & -0.286 & -0.083 & -0.226 & -0.249 & -0.150 & -0.197 & -0.211 & -0.112 \\
\hline StdErr & 0.082 & 0.058 & 0.049 & 0.066 & 0.045 & 0.052 & 0.056 & 0.041 & 0.047 \\
\hline tValue & -2.510 & -4.968 & -1.709 & -3.447 & -5.571 & -2.894 & -3.493 & -5.094 & -2.381 \\
\hline Probt & 0.022 & 0.000 & 0.106 & 0.003 & 0.000 & 0.010 & 0.003 & 0.000 & 0.029 \\
\hline
\end{tabular}


The restriction $\beta_{2}=0$ is imposed (i.e., incidence growth is excluded) in the equations shown in columns 1,4 , and 7 . The estimate of $\beta_{1}$ is not statistically significant in any of these six equations. As Welch et al observed, there is "little correlation between the change in 5-year survival for a specific tumor and the change in tumor-related mortality" when we don't control for the change in incidence.

The restriction $\beta_{1}=0$ is imposed (i.e., conditional mortality growth is excluded) in the equations shown in columns 2,5 , and 8 . The estimate of $\beta_{2}$ is positive and statistically significant in some equations but not in others.

No restrictions are imposed (i.e., both conditional mortality growth and incidence growth are included) in the equations shown in columns 3,6 , and 9 . In all six equations, both $\beta_{1}$ and $\beta_{2}$ are positive and significant. The highest $p$-value for a $\beta_{1}$ estimate is .048 ; the other p-values are .012 or lower. When incidence growth is controlled for, there is a highly significant correlation between the change in 5-year survival for a specific tumor and the change in tumor-related mortality in both the U.S. and Australia, whether observations are equally weighted, weighted by the mean of the initial and final incidence rates, or weighted by the mean of the initial and final unconditional mortality rates. It is also interesting to note that the estimates of $\beta_{2}$ are larger when conditional mortality growth is included than they are when conditional mortality growth is excluded.

The correlation between unconditional and conditional mortality growth, controlling for incidence growth, may be depicted graphically, as follows. First, compute the residuals from the simple regression of unconditional mortality growth on incidence growth (uncond_resid). Next, compute the residuals from the simple regression of conditional mortality growth on incidence growth (cond resid), and plot uncond resid against cond resid. Figure 2 shows bubble scatterplots, in which the size of a bubble is proportional to the mean of the cancer site's initial and final unconditional mortality rates.

As shown in Table 1, in both the U.S. and Australia, both mean cancer incidence rates and relative survival rates have increased. In the following table, I use the estimates in column 9 of Table 2 to assess the impact of these changes on the mean change in the unconditional mortality rate. 
Figure 2

Correlation across cancer sites between growth in unconditional mortality and growth in conditional mortality, controlling for growth in incidence
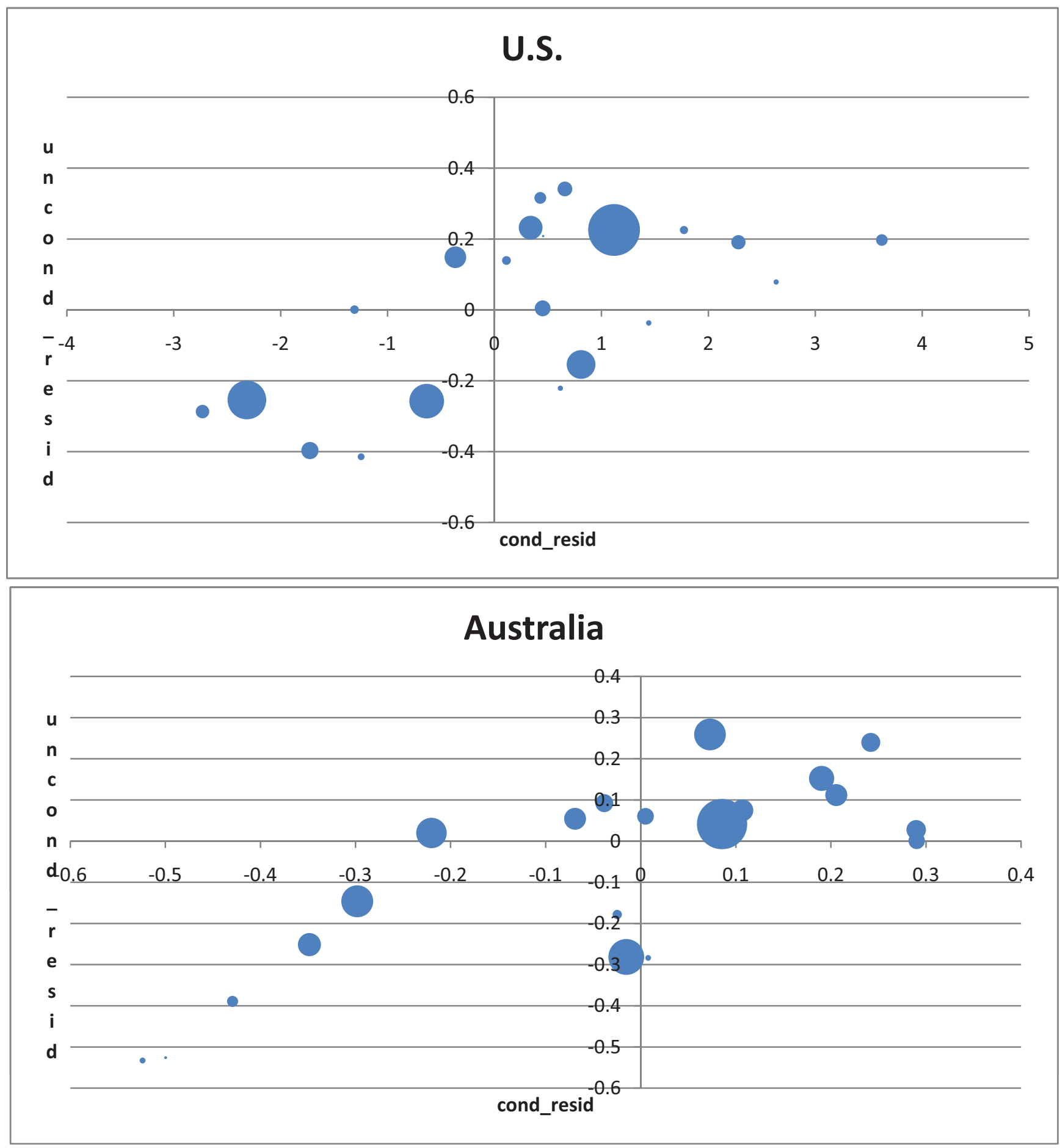

Note: uncond_resid is the residual from the simple regression of unconditional mortality growth on incidence growth; cond_resid is the residual from the simple regression of conditional mortality growth on incidence growth; the size of a bubble is proportional to the mean of the cancer site's initial and final unconditional mortality rates. 


\begin{tabular}{|c|c|c|c|}
\hline & & U.S. & Australia \\
\hline $\begin{array}{c}\text { mean change in unconditional } \\
\text { mortality rate }\end{array}$ & mean $(\Delta \ln ($ mort_uncond $))$ & -0.180 & -0.184 \\
\hline $\begin{array}{c}\text { predicted change due to } \\
\text { increasing relative survival }\end{array}$ & $\begin{array}{c}\beta_{1} \text { mean }(\Delta \ln (1- \\
\text { surv_5_year }))\end{array}$ & -0.146 & -0.151 \\
\hline $\begin{array}{c}\text { predicted change due to rising } \\
\text { incidence }\end{array}$ & $\beta_{2}$ mean $(\Delta \ln ($ incidence $))$ & 0.111 & 0.079 \\
\hline unexplained change & $\alpha$ & -0.146 & -0.112 \\
\hline
\end{tabular}

In both countries, the unconditional mortality rate declined by about $18 \%$, and the increase in the relative survival rate is estimated to have reduced the unconditional mortality rate by about $15 \%$. The increase in the incidence rate is estimated to have increased the unconditional mortality rate by $11 \%$ in the U.S. and $8 \%$ in Australia. In both countries, there was a substantial decline in unconditional mortality that is not explained by changes in either relative survival or incidence. This may be attributable to factors other than improvements in medical knowledge about cancer, such as better treatment of heart disease (Honore and Lleras-Muney (2004)).

\section{Comment}

While the change in the 5-year survival rate is not a perfect measure of progress against cancer, in part because it is potentially subject to lead-time bias, the evidence we have presented indicates that it does contain useful information, and that its critics may have been unduly harsh.

When incidence growth is controlled for, there is a highly significant correlation, in both the U.S. and Australia, between the change in 5-year survival for a specific tumor and the change in tumor-related mortality. The increase in the relative survival rate is estimated to have reduced the unconditional mortality rate by about $15 \%$ in the U.S. between 1976 and 2002, and by about $15 \%$ in Australia between 1984 and 2001.

Controlling for incidence growth has an important effect on the correlation between unconditional mortality growth and relative survival growth because there is a strong positive correlation between incidence growth and relative survival growth. Welch et al argued that "in the classic epidemiology model, no relationship would be expected between incidence and 5-year survival (unless there is some concurrent change in tumor biology)...how many people developed

\footnotetext{
${ }^{6}$ Means in this table are weighted by the mean of the cancer site's initial and final unconditional mortality rates.
} 
disease would not be expected to influence the prognosis of the individual case (e.g., 5-year survival)." However, we think there are two reasons why the prognosis of the individual case should depend on the number of people developing the disease.

The first reason is that the greater the number of people with a disease, the more research will be devoted to it, and the more treatments will be developed. Lichtenberg (2007) found that there is a significant positive correlation across cancer sites between incidence and both (1) the amount of research investment (measured by the number of articles published in scientific journals pertaining to the cancer site), and (2) the number of distinct chemotherapy regimens for treating cancer at that site. Indeed, the underlying premise of the 1983 Orphan Drug Act is that, unless the government provides special incentives, diseases with low incidence will attract little R\&D investment and therefore will have poor outcomes (Lichtenberg and Waldfogel (2009)).

A second possible reason for a positive correlation between the change in incidence and the change in relative survival is experience and learning by clinicians. As Barocas et al (2009) observe, a positive association between both surgeon and hospital case volume and outcomes has been established in the case of cardiovascular surgery and for several high-risk cancer operations; they also document a relationship between case volume and outcomes after radical prostatectomy. While most of the evidence for a positive relationship between case volume and outcomes is at the physician or hospital level, a positive relationship at the aggregate or societal level also seems plausible: the more experience the entire healthcare system has with treating a disease (because its incidence is high), the better the outcome of the average patient.

Our finding that the change in the relative survival rate is inversely correlated across cancer sites with the change in the unconditional mortality rate when we control for the growth in incidence provides some evidence for the hypothesis that gains in 5-year survival over time are partly due to improved prevention, screening, or therapy. Several recent studies have provided another type of evidence that supports this hypothesis: they have shown that the change or difference in the 5-year survival rate is positively correlated with the change or difference in the number of treatments available to treat cancer. Using longitudinal, cancer-site-level data on U.S. cancer patients during the period 1978-2004, Lichtenberg (2009a) found that the introduction (FDA approval) of new cancer drugs had a positive effect on survival rates, controlling for cancer stage distribution, mean age at diagnosis, and incidence. The impact of an additional FDA approval on the survival rate tends to increase steadily for a number of years, peak about 8-12 years after launch, and then decline. This finding is consistent with evidence about the product life cycle of cancer drugs: utilization tends to increase steadily after FDA approval, peak about 6-10 years 
after launch, and then decline. Lichtenberg (2009b) investigated the effect of availability of new drugs on survival from 17 types of cancer in 38 countries, controlling for all determinants of cancer survival that are invariant across cancer types within a given country, and that are invariant across countries for a given cancer type. He found that an increase in the number of available drugs is associated with an increase in the five-year survival rate. 
Appendix Table 1

US mortality, relative survival, and incidence rates, by cancer site (ranked by initial mortality rate)

\begin{tabular}{|l|c|c|c|c|c|c|}
\hline \multirow{2}{*}{ Site } & \multicolumn{2}{|c|}{$\begin{array}{c}\text { Age-adjusted } \\
\text { mortality rate }\end{array}$} & \multicolumn{2}{c|}{$\begin{array}{c}\text { 5-year relative survival } \\
\text { rate }\end{array}$} & \multicolumn{2}{c|}{$\begin{array}{c}\text { Age-adjusted } \\
\text { incidence rate }\end{array}$} \\
\hline & $\mathbf{1 9 8 0}$ & $\mathbf{2 0 0 6}$ & $\mathbf{1 9 7 5 - 1 9 7 7}$ & $\mathbf{1 9 9 9 - 2 0 0 5}$ & $\mathbf{1 9 7 6}$ & $\mathbf{2 0 0 2}$ \\
\hline Lung and Bronchus & 49.4 & 51.7 & $12.7 \%$ & $16.3 \%$ & 55.4 & 63.7 \\
\hline Prostate & 33.1 & 23.6 & $68.9 \%$ & $99.9 \%$ & 97.9 & 180.5 \\
\hline Colon and Rectum & 28.1 & 17.1 & $50.8 \%$ & $66.8 \%$ & 61.4 & 52.7 \\
\hline Breast & 18.0 & 13.2 & $75.2 \%$ & $90.1 \%$ & 56.4 & 73.0 \\
\hline Pancreas & 10.6 & 10.8 & $2.5 \%$ & $5.6 \%$ & 12.0 & 11.7 \\
\hline Ovary & 9.3 & 8.5 & $37.2 \%$ & $45.6 \%$ & 15.9 & 13.7 \\
\hline Stomach & 7.4 & 3.7 & $15.9 \%$ & $26.5 \%$ & 12.2 & 7.9 \\
\hline Urinary Bladder & 5.2 & 4.3 & $73.5 \%$ & $81.7 \%$ & 19.7 & 21.1 \\
\hline Cervix Uteri & 4.5 & 2.4 & $69.9 \%$ & $71.8 \%$ & 14.3 & 7.4 \\
\hline Esophagus & 3.8 & 4.4 & $5.1 \%$ & $18.8 \%$ & 4.3 & 4.6 \\
\hline Kidney and Renal Pelvis & 3.7 & 4.0 & $50.9 \%$ & $69.1 \%$ & 8.0 & 12.8 \\
\hline Myeloma & 3.3 & 3.5 & $25.9 \%$ & $37.1 \%$ & 5.0 & 5.9 \\
\hline Acute Myeloid Leukemia & 2.5 & 2.8 & $6.6 \%$ & $23.4 \%$ & 3.5 & 3.6 \\
\hline Melanoma of the Skin & 2.3 & 2.7 & $82.4 \%$ & $93.0 \%$ & 8.2 & 19.1 \\
\hline Larynx & 1.6 & 1.2 & $66.6 \%$ & $63.2 \%$ & 5.2 & 3.5 \\
\hline & & & & & & \\
\hline Chronic Lymphocytic Leukemia & 1.5 & 1.4 & $69.0 \%$ & $78.8 \%$ & 4.6 & 4.6 \\
\hline Gallbladder & 1.2 & 0.6 & $9.0 \%$ & $15.1 \%$ & 1.7 & 1.2 \\
\hline Soft Tissue including Heart & 1.2 & 1.3 & $61.3 \%$ & $68.5 \%$ & 2.2 & 3.0 \\
\hline Chronic Myeloid Leukemia & 1.0 & 0.3 & $23.9 \%$ & $53.3 \%$ & 1.9 & 1.6 \\
\hline & & & & & & \\
\hline Acute Lymphocytic Leukemia & 0.6 & 0.5 & $42.4 \%$ & $66.3 \%$ & 1.1 & 1.5 \\
\hline Bones and Joints & 0.6 & 0.4 & $53.9 \%$ & $70.3 \%$ & 0.8 & 0.9 \\
\hline Testis & 0.5 & 0.2 & $82.7 \%$ & $96.2 \%$ & 3.4 & 5.7 \\
\hline Thyroid & 0.5 & 0.5 & $93.2 \%$ & $97.3 \%$ & 4.8 & 9.1 \\
\hline Acute Monocytic Leukemia & 0.1 & 0.0 & $0.0 \%$ & $23.5 \%$ & 0.3 & 0.3 \\
\hline Eye and Orbit & 0.1 & 0.1 & $83.2 \%$ & $83.8 \%$ & 0.8 & 0.8 \\
\hline
\end{tabular}


Appendix Table 2

Australian mortality, relative survival, and incidence rates, by cancer site (ranked by initial mortality rate)

\begin{tabular}{|l|c|c|c|c|c|c|}
\hline & \multicolumn{2}{|c|}{$\begin{array}{c}\text { Age-adjusted } \\
\text { mortality rate }\end{array}$} & \multicolumn{2}{c|}{$\begin{array}{c}\text { 5-year relative survival } \\
\text { rate }\end{array}$} & \multicolumn{2}{c|}{$\begin{array}{c}\text { Age-adjusted } \\
\text { incidence rate }\end{array}$} \\
\hline & 1987 & 2003 & $1982-1986$ & $1998-2004$ & 1982 & 1998 \\
\hline Lung (C33-C34) & 41.4 & 34.3 & $8.5 \%$ & $11.8 \%$ & 46.9 & 44.4 \\
\hline Colon (C18) & 23.6 & 14.8 & $48.9 \%$ & $61.3 \%$ & 38.1 & 40.8 \\
\hline Breast (C50) & 17.2 & 13.3 & $71.8 \%$ & $87.8 \%$ & 43.8 & 60.1 \\
\hline $\begin{array}{l}\text { Unknown primary site (C26, } \\
\text { C39, C76, C80) }\end{array}$ & 14.9 & 15.2 & $6.0 \%$ & $9.1 \%$ & 18.8 & 17.5 \\
\hline Prostate (C61) & 13.9 & 13.9 & $57.4 \%$ & $85.3 \%$ & 31.2 & 56.2 \\
\hline Stomach (C16) & 10.3 & 5.7 & $16.9 \%$ & $24.7 \%$ & 15.7 & 10.6 \\
\hline Pancreas (C25) & 9.7 & 9.2 & $2.8 \%$ & $4.6 \%$ & 9.8 & 10.1 \\
\hline Rectum (C19-C20) & 7.6 & 6.7 & $48.4 \%$ & $62.9 \%$ & 20.0 & 21.4 \\
\hline Leukaemia (C91-C95) & 7.6 & 6.8 & $37.6 \%$ & $47.8 \%$ & 11.8 & 12.9 \\
\hline $\begin{array}{l}\text { Non-Hodgkin lymphoma } \\
\text { (C82-C85, C96) }\end{array}$ & 7.2 & 7.2 & $46.9 \%$ & $62.1 \%$ & 12.8 & 17.7 \\
\hline Melanoma of skin (C43) & 5.7 & 5.6 & $86.5 \%$ & $91.6 \%$ & 26.1 & 43.8 \\
\hline Bladder (C67) & 5.4 & 4.3 & $68.0 \%$ & $60.4 \%$ & 18.0 & 12.2 \\
\hline Brain (C71) & 5.3 & 5.5 & $20.4 \%$ & $18.9 \%$ & 6.3 & 6.5 \\
\hline Ovary (C56) & 4.5 & 3.8 & $32.7 \%$ & $39.8 \%$ & 6.6 & 6.2 \\
\hline Kidney (C64) & 4.1 & 3.9 & $46.5 \%$ & $65.8 \%$ & 6.2 & 10.2 \\
\hline Cervix (C53) & 2.5 & 1.2 & $68.3 \%$ & $71.8 \%$ & 7.3 & 4.7 \\
\hline Uterus, body (C54) & 1.5 & 1.1 & $75.6 \%$ & $82.1 \%$ & 7.0 & 7.7 \\
\hline Hodgkin lymphoma (C81) & 0.7 & 0.3 & $71.7 \%$ & $85.2 \%$ & 2.2 & 2.1 \\
\hline Thyroid (C73) & 0.6 & 0.4 & $83.6 \%$ & $93.4 \%$ & 2.8 & 5.3 \\
\hline Testis (C62) & 0.2 & 0.1 & $90.8 \%$ & $96.8 \%$ & 2.1 & 3.0 \\
\hline
\end{tabular}




\section{References}

Bailar J, Gornik H (1997), "Cancer undefeated," New England Journal of Medicine 336 (22), pp. 1569-74.

Barocas DA, Mitchell R, Chang SS, Cookson MS (2009), "Impact of surgeon and hospital volume on outcomes of radical prostatectomy," Urol Oncol. Apr 21.

Honoré, Bo, and Adriana Lleras-Muney (2006), "Competing Risks and the War on Cancer," Econometrica, Vol. 74, Issue 6, November.

Leaf, Clifton (2004), "Why we're losing the war on cancer, and how to win it," Fortune, March $22<\underline{\text { http://blog.aperio.com/articles/Fortune_Cancer.pdf }>}$

Lichtenberg, Frank R. (2007), "Importation and innovation," Economics of Innovation and New Technology 16(6), September, pp. 403-417.

Lichtenberg, Frank R. (2009a), "The effect of new cancer drug approvals on the life expectancy of American cancer patients, 1978-2004," Economics of Innovation and New Technology 18 (5), 407-28.

Lichtenberg, Frank R. (2009b), "International differences in cancer survival rates: the role of new drug launches," International Journal of Healthcare Technology and Management 10 (3), 138-55.

Lichtenberg, Frank R., and Joel Waldfogel (2009), "Does Misery Love Company? Evidence from Pharmaceutical Markets before and after the Orphan Drug Act," 15 Mich. Telecomm. Tech. L. Rev., available at http://www.mttlr.org/volfifteen/lichtenberg\&waldfogel.pdf

Welch, H. Gilbert, Lisa M. Schwartz, and Steven Woloshin (2000), "Are Increasing 5-Year Survival Rates Evidence of Success Against Cancer?," JAMA 283(22): 2975-2978 (doi:10.1001/jama.283.22.2975) 